


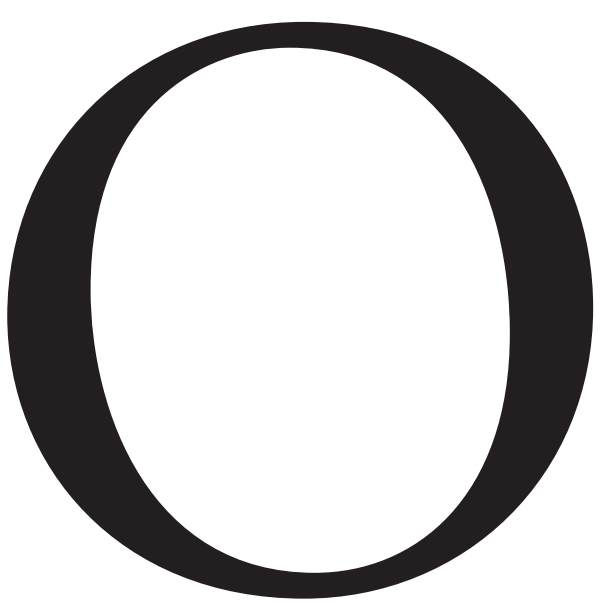

IRIS KANTOR

LAURA DE MELLO E SOUZA

s duzentos anos da chegada da família real portuguesa vêm sendo lembrados de formas variadas no Brasil e em Portugal: aqui, evoca-se, sobretudo, o papel que o fato teve no processo que culminou com a fundação da nação; lá, tem-se dado maior relevo à guerra peninsular, na qual a atuação portuguesa foi valorosa e contribuiu decisivamente para expulsar o invasor francês. Sem desconsiderar a importância dessas análises, nem tampouco as transformações acarretadas pela presença dos Braganças em solo americano - abertura dos portos ao comércio internacional, e das terras luso-americanas à visita de viajantes estrangeiros; criação da Casa da Moeda, do Jardim Botânico, da Biblioteca Nacional, etc. -, no geral vistas sob a perspectiva do nascimento da nação independente, o número comemorativo da Revista USP propõe um enfoque distinto, indo em sentido diverso do que até agora se percorreu. Desloca o foco de análise, ultrapassando o exame das continuidades e rupturas, sempre presente nas interpretações acerca do evento; propõe que se explore 1808 como acontecimento que teve impactos imediatos, conjunturais, e produziu, simultaneamente, transformações profundas e duradouras, mais referidas aos fenômenos estruturais: alterando não apenas o quadro das relações internacionais, como

IRIS KANTOR

é professora do

Departamento de História da FFLCH-USP e autora de Esquecidos e Renascidos (Hucitec).

\section{LAURA DE MELLO E} SOUZA é professora do Departamento de História da FFLCH-USP e autora de, entre outros, 0 Sol e a Sombra (Companhia das Letras). o sistema imperial no seu conjunto.

Os textos reunidos neste volume ilustram tal perspectiva. Alguns se detêm no tempo do acontecimento e registram seus ecos e reverberações de momento, presentes com intensidade, por exemplo, nas gazetas e correspondência diplomática: Lúcia Bastos Pereira das Neves, Neil Safier, Raquel Stoiani, João Paulo Garrido Pimenta e Adriana Salay Leme revelam como a viagem da corte joanina foi acompanhada com interesse e 
sil para a indústria da Grã-Bretanha, país interessadíssimo, portanto, nos destinos de Portugal e de seu império, o que ajuda a entender o protagonismo britânico no episódio da fuga, aliás já arquitetada a partir de Londres desde 1805. Rafael Marquese e João José Reis sublinham a intensificação do tráfico negreiro nessa conjuntura e mostram, sob ângulos distintos, que D. João se tornaria, irreversivelmente, um monarca negreiro: internamente, a repressão contra quilombos e práticas mágico-religiosas ganharia impulso; externamente, o modelo conservador mas renovado que o Brasil passou a corporificar serviu de exemplo a Cuba, região que continuou colonial e profundamente escravista, como nós.

Que colônias mais distantes - recémemancipadas, como os Estados Unidos, ou ainda conformadas aos quadros do sistema colonial, como Cuba-e vizinhos de fronteira, como os rio-platenses, acompanhassem com atenção o que se ia passando entre Lisboa e o Rio de Janeiro é fácil de entender. Mais inesperado é que a viagem da corte ecoasse, como ecoou, para além do mundo atlântico: Tiago dos Reis Miranda traz um episódio pouco conhecidoe contemporâneo às vicissitudes dos Braganças, ou seja, a proposta enviada aos franceses de negociar pela via diplomática a cessão das ilhas de Timor e Solor em troca da recuperação de Olivença, perdida quando da Guerra das Laranjas (1801-02). Bernardo José de

D. João VI em tela de José

Inácio S. Paio, 1824 ansiedade pelos rio-platenses e pela jovem nação norte-americana, as notícias da guerra na Europa repercutindo no Rio de Janeiro e servindo de reforço ao poder da dinastia bragantina enquanto, na antiga metrópole, os portugueses se dividiam entre a urgência de expulsar o inimigo francês, a tentação de fazer de Junot um rei e, assim, reinventar o absolutismo monárquico, oódio aos ingleses - que tinham viabilizado a retirada real - e aos “brasileiros", colonos da véspera, a partir de então tornados próximos do poder real.

Mas os textos aqui reunidos revelam também as novas articulações capazes de gerar mudanças estruturais. José Jobson de Andrade Arruda destaca a importância crescente da produção algodoeira do Bra-
Lorena, governador de São Paulo e depois de Minas Gerais, terminou como vice-rei da Índia, de onde escreveu detalhadamente sobre a situação de Timor: personagem que conecta as diferentes partes do império, trajetória que encarna a relação estrutural existente sob a espuma dos acontecimentos, como diria Fernand Braudel.

Em meio a tantas mudanças, persistiram imagens seculares veiculadas sobre o Brasil, perduraram práticas de exclusão e de violência cotidiana. Lilia Schwarcz mostra como o Brasil idealizado pelos artistas franceses de então - bonapartistas desconfortáveis ante a restauração burbônica - , ainda tinha muito do mundo edênico que atraíra homens como Thevet e Léry três séculos antes, sendo 
capaz de fazê-los cruzar o oceano, quase de livre e espontânea vontade, para formarem a "Missão Francesa", que a autora apresenta sob cores novas. João Reis, Regina Celestino e Edu Otsuka lembram que, para negros, índios e pobres urbanos, a chegada da corte mudou muito pouco, mesmo que houvesse a expectativa de que mudasse muito: "dono da Terra chegou, cento e cinquienta acabou", teriam cantado os negros da Bahia, esperançosos de que os açoites terminassem. Quando D. João deixou Salvador rumo ao Rio, contudo, o intolerante governador teria mandado afixar nos lugares públicos: “Dono da Terra abalou, cento e cinqüenta voltou”! Os índios, por sua vez, puderam, pela primeira vez, negociar com um rei de corpo presente, mas, a médio prazo, sofreram na carne a inelutável desestruturação das aldeias que tinham antes pontilhado o sertão da capitania fluminense. A monarquia joanina continuaria refratária aos costumes locais, já misturados e, muitas vezes, distantes dos europeus: Edu Otsuka retoma a análise de um texto clássico das letras brasileiras, Memórias de um Sargento de Milícias, em que a dialética da exclusão e da incorporação, da ordem e da desordem encontra-se expressa de modo exemplar. Elididos do romance, os escravos assombravam as mentes dos administradores - que o diga o conde da Ponte, tão bem delineado no texto de João Reis. Quisesse ou não, conforme demonstram Reis e Marquese, D. João era, afinal, o chefe supremo de um império escravista.

1808 remete ao nascimento do Brasil porque, nos anos subseqüientes, nos tornaríamos uma grande nação americana. Este dossiê procurou indicar o significado muito mais abrangente, global até, do acontecimento, deslocando o ponto de observação para fora e considerando a exterioridade tanto em termos geográficos quanto ideológicos e sociais. Talvez o alcance evidente do fato histórico tenha quase sempre permanecido oculto porque importava pouco à construção da memória nacional, que, assim, o desbastou e recortou para melhor se apossar dele. Alargar o foco da análise e indicar a amplitude do fenômeno, por sua vez, ultrapassa essa perspectiva mais usual e mostra o quanto foi partilhado, observado de longe por vários olhos, os fatos, amparados em informações - como observa Garrido Pimenta -, gerando boatos e os boatos criando fatos novos. A vinda da família real portuguesa para o Brasil em 1808 repercutiu em contextos diversos e inusitados, produzindo sentidos que merecem estudos atentos: esperamos que, daqui em diante, essa perspectiva renda muitos frutos.

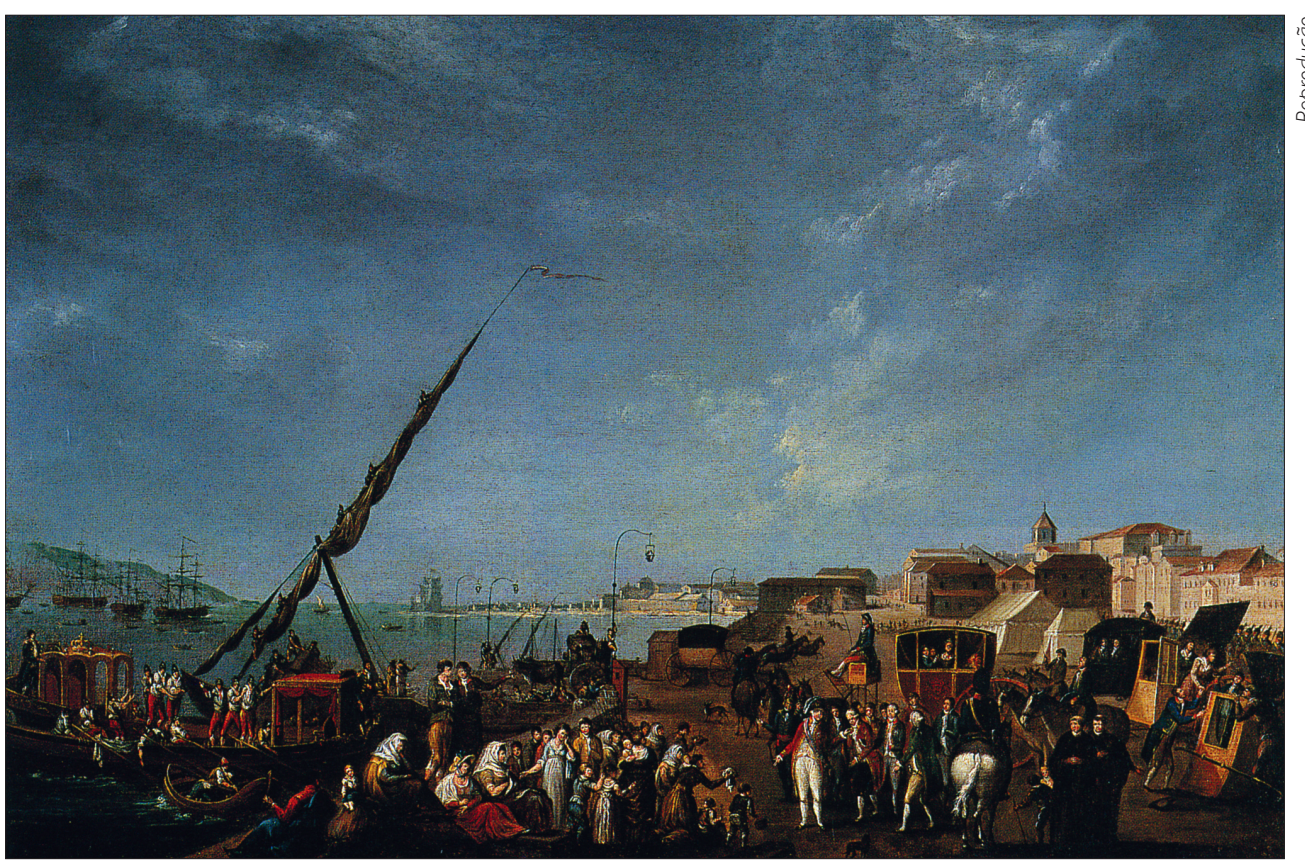

Embarque para o Brasil, de Nicolas Louis Albert Delerive, 1807-18 